\title{
POROSITY DEVELOPMENT DURING STEAM ACTIVATION OF CARBON FOAMS FROM CHEMICALLY MODIFIED PITCH
}

Boyko Tsyntsarski $^{1 *}$, Bylana Petrova ${ }^{1}$, Temenuzhka Budinova ${ }^{1}$, Narzislav Petrov ${ }^{1}$, Leticia F. Velasco ${ }^{2}$, José B. Parra², Conchi O. Ania*²

${ }^{1}$ Institute of Organic Chemistry, Bulgarian Academy of Sciences, Acad. G. Bonchev str., BL.9, 1113 Sofia 1113, Bulgaria

${ }^{2}$ Instituto Nacional del Carbon, INCAR-CSIC, Apartado 73, 33080, Oviedo, Spain

*Corresponding author. Fax: +35928700225 / +34 985297662

E-mail address: goriva@orgchm.bas.bg (B Tsyntsarski) or conchi.ania@incar.csic.es (CO. Ania)

\begin{abstract}
The steam activation of carbon foams obtained after a thermo-oxidation treatment of coal tar pitch using inorganic acids $\left(\mathrm{H}_{2} \mathrm{SO}_{4}\right.$ and $\left.\mathrm{HNO}_{3}\right)$, based on a low pressure foaming process without stabilization step was investigated. The characterization of the activated foams showed a strong dependence of the final structure of these materials with the chemical composition of the pitch precursor. This was related to the nature of the acidic pre-treatment used to modify the composition of the initial pitch. In both cases carbon foams with uniform open cell structures were obtained, although they showed very different steam reactivities. When nitric acid was used in the initial thermo-oxidative treatment, the activation of the carbon foam proceeded to a large extent; the porosity parameters of this sample were twice higher than those obtained when using sulfuric acid. This was attributed to the catalytic effect of $\mathrm{H}_{2} \mathrm{SO}_{4}$ during the foaming step, which led to the formation of dense carbon foams with a well organized structure as inferred from XRD. At converse, densification of the foam did not occur when using nitric acid; the resulting material displayed labile surface groups decomposing at moderate temperatures, as well as an incipient microporosity before activation, which was further enlarged during the steam activation.
\end{abstract}


Keywords: carbon foam; pore structure; thermo-oxidation; steam activation

\section{Introduction}

Carbon foams are sponge-like ultra-high performance engineering materials which have recently attracted attention due to their potential applications in numerous fields $[1,2]$. This interest has arisen from their outstanding features such as good electrical, optical, thermal and mechanical stability, coupled with tailorable thermal and electrical conductivities. Originally prepared from polymeric precursors [3-6], the development of carbon foams from coal tar and petroleum pitches [7-9], as well as biomass derived precursors [10-12] provides an economical path for the synthesis of lightweight carbon materials.

The effect of the precursor's nature and foaming process on the structure and properties of the foams is under extensive investigation [13-15]. Typically, carbon foams have been prepared at high temperatures and high pressures [16,17], these two factors being key parameters to control the final properties of the carbon foam. However, the usual rigorous synthesis conditions and their associated high costs have limited their applications; thus from practical and industrial points of view, novel synthetic pathways based on lower pressures and temperatures are required.

When coal-derived pitches are used as precursors, a preliminary treatment is usually required before the foaming process, in order to adjust the viscosity and plastic properties of the pitch that would allow an effective foaming process. Such pretreatments usually involve polymerization and condensation reactions in the pitch. Air blowing and thermo-chemical treatment are most widely applied pre-treatments to control the viscosity and degree of anisotropy of the foaming precursor $[18,19]$. In this regard, we have recently reported the synthesis of carbon foams from coal tar pitches using a low pressure foaming synthesis, based on the 
modification of the foam precursor with mineral acids [20]. This process requires neither a stabilization step nor high pressure treatments, thus reducing both the manufacturing time and the cost of the carbon foam. Moreover, therein reported foams exhibited outstanding mechanical properties [20], and a good performance as catalysts supports [21].

A way to broaden the application fields towards their use as adsorbents in liquid [3] and gas phase [22], as well as their utilization as catalysts supports [21, 23] would rely on increasing their surface area (activation). Notwithstanding, the activation procedure has to be carried out under suitable conditions to ensure the porosity development while preserving the morphology of the pristine material.

For this reason, the objective of this study was to investigate the steam activation of carbon foams prepared from thermo-oxidized pitches $\left(18 \mathrm{M} \mathrm{H}_{2} \mathrm{SO}_{4}\right.$ and $\left.16 \mathrm{M} \mathrm{HNO}_{3}\right)$ based on a low pressure foaming. The effect of the pitch precursor composition on the properties of the carbon foam (structural parameters and reactivity for porous development) was evaluated. This will contribute to better comprehend the thermochemical reactions occurring during the foaming process to obtain low cost foams with a well developed porosity within the micro/mesopore range.

\section{Experimental Methods}

\subsection{Foaming precursor and pretreatment}

A commercial coal tar pitch was used as precursor (sample P) and was initially subjected to a chemical modification with concentrated acids (at $120^{\circ} \mathrm{C}$. The aim of this modification is to reduce the plastic properties of the pitch and therefore to allow the foaming process to be conducted at low pressure. Briefly, the coal tar pitch was heated up to $120^{\circ} \mathrm{C}$ to ensure melting conditions, and then the acid was added slowly under continuous stirring until a solid product 
was obtained. The samples were subsequently washed with hot distilled water to remove the excess of the reactant. The modified pitches were labeled as PS and PN, for the treatment carried out with sulfuric and nitric acids, respectively. The foaming process was carried out in a ceramic vessel by heating the pitch up to $600^{\circ} \mathrm{C}$ (heating rate $15^{\circ} \mathrm{C} / \mathrm{min}$ ), in a $\mathrm{N}_{2}$ atmosphere for $30 \mathrm{~min}$. The resulting carbon foams were labeled as CF followed by S and N, for those obtained by the modification in sulfuric and nitric acids, respectively. The obtained "green" foams were pyrolyzed at $800^{\circ} \mathrm{C}$ in $\mathrm{N}_{2}$ atmosphere (heating rate $15^{\circ} \mathrm{C} / \mathrm{min}$ ) for further evolving of volatiles, and subsequently steam activated for $60 \mathrm{~min}$ at the same temperature. Activated carbon foams will be labeled followed by "-A".

\subsection{Characterization of the pitches and carbon foams}

Elemental analysis of the as-received and modified pitches was carried out in LECO automatic analyzers (CHNS-932 and VTF-900 for the oxygen content). The materials (pitches and synthesized carbon foams) were further characterized by thermogravimetric analysis

(Setaram Labsys) employing the following instrument settings: heating rate of $15^{\circ} \mathrm{C} \mathrm{min}^{-1}$; argon

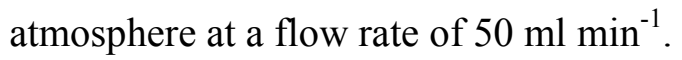

X-Ray diffraction (XRD) patterns were recorded on a Bruker D8 Advance instrument operating at $40 \mathrm{kV}$ and $40 \mathrm{~mA}$, scan rate $0.02 \theta \mathrm{s}^{-1}$ and using $\mathrm{Cu} \mathrm{K} \alpha(\lambda=0.15406 \mathrm{~nm})$ radiation. Morphology of the carbon foam particles was studied using a Ziess DSM 942 scanning electron microscope; particles were dispersed on a graphite adhesive tab placed on an aluminum stub. The images were generated in the back scattered electron signal mode, which yielded better quality pictures. 
Both bulk (geometric) and true (helium) densities were measured to determine the bulk porosity of the block samples. The bulk density was evaluated from the values of the weight and the volume - the latter was calculated using dimensions of the sample. The true density was determined by helium pycnometry (Micromeritics). The bulk porosity $(\mathrm{P})$ was calculated using the expression $P(\%)=100 \times\left(\left(D_{\mathrm{t}}-D_{\mathrm{b}}\right) /\left(D_{\mathrm{t}}\right)\right)$, where, $D_{\mathrm{t}}$ and $D_{\mathrm{b}}$ are true and bulk densities of a sample, respectively.

Textural characterization of the carbon foams was carried out by $\mathrm{N}_{2}$ and $\mathrm{CO}_{2}$ adsorptiondesorption isotherms at $-196{ }^{\circ} \mathrm{C}$ and $0{ }^{\circ} \mathrm{C}$, respectively. Before the experiments, the samples were outgassed under secondary vacuum at $120^{\circ} \mathrm{C}$ overnight. The isotherms were used to calculate the specific surface area, $\mathrm{S}_{\mathrm{BET}}$, total pore volume, $\mathrm{V}_{\mathrm{T}}\left(\right.$ evaluated at $\left.\mathrm{p} / \mathrm{p}_{0} 0.99\right)$, and pore size distributions applying the t-plot method and using a non-porous carbon coated silica as standard [24]. The volume of narrow micropores was evaluated from the DRS formulism applied to the $\mathrm{CO}_{2}$ adsorption data, using $1.023 \mathrm{~g} / \mathrm{cm}^{3}$ as the density of adsorbed $\mathrm{CO}_{2}$ and 0.36 as the value of the $\beta$ parameter [25].

\section{Results and discussion}

\subsection{Characterization of the carbon foams}

In a recent work we have reported the synthesis of carbon foams using coal tar pitch as precursor based on the thermo-oxidative modification of the pitch precursor with mineral acids [20]. A detailed analysis on the chemical composition of the coal tar pitch after the acid modification has been therein discussed. Here we merely report the main physicochemical and structural parameters of the raw precursors for data interpretation (Table 1). 
Briefly, the selected coal tar pitch (sample $\mathrm{P}$ ) is characterized by a low softening point and low oxygen content, both being largely increased after the acid treatments. This modification allows the foaming process to be conducted at low pressure. The increase in the oxygen content is attributed to the formation of oxygen containing groups during the thermo-oxidation treatment, as a consequence of polymerization and polycondensation reactions. This effect was slightly more pronounced when using sulfuric acid. Besides the oxygen, the acid modification caused a slight increase in the nitrogen and sulfur content of the pitch treated in nitric and sulfuric acids, respectively.

The synthesized carbon foams prepared from the low pressure foaming of the modified pitches are characterized by a reticular vitreous structure (Figure 1). This open cell wall structure is frequently found in foams prepared by pyrolysis of polymers, pitches and coal extracts [7]. The foam cells presented an average size between ca. 200-250 $\mu \mathrm{m}$ after the treatment in sulfuric acid, and were slightly larger (ca. 300-350 $\mu \mathrm{m}$ ) for that obtained after nitric acid modification of the pitch. The SEM images clearly showed the presence of cracks in the matrices of both materials, indicative of a well-developed foaming step [26]. These cracks mainly occur between the layers aligned parallel to the cell surface, especially in the junction area of the foam cells. The bulk (geometric) densities of the carbon foams were 0.52 and $0.59 \mathrm{~g} / \mathrm{cm}^{3}$, respectively, for CFS and CFN, which are relatively high values for the operating pressure used in this study [10]. The foams also have over $89 \%$ open cell structure with bulk porosity close to $70 \%$ according to helium pycnometry.

Both CFS and CFN showed a smooth surface with a low porosity at a nanometric scale and surface areas of ca. $25 \mathrm{~m}^{2} \mathrm{~g}^{-1}$. The corresponding gas adsorption isotherms $\left(\mathrm{N}_{2}\right.$ and $\mathrm{CO}_{2}$ at $196^{\circ} \mathrm{C}$ and $0^{\circ} \mathrm{C}$, respectively) are shown in Figure 2, whereas the main textural parameters are compiled in Table 2. According to the $\mathrm{N}_{2}$ adsorption isotherms at $77 \mathrm{~K}$, before activation none of 
the pristine carbon foams exhibited any porosity in the micropore or mesopore range (as it is characteristic of reticular vitreous materials). However, a deep analysis of the porosity by means of the $\mathrm{CO}_{2}$ adsorption data showed the presence of a non-negligible micropore volume for CFN. This indicates that kinetic restrictions hinder the accessibility of $\mathrm{N}_{2}$ to the porosity of this sample [27], which should then be composed of micropores of narrow sizes. Indeed, the pore size distribution of narrow micropores was evaluated by the equation proposed by Dubinin-Stoeckli (DS) [25] from the $\mathrm{CO}_{2}$ adsorption isotherms and the obtained data (Figure 3) corroborated the presence of micropores of ca. $0.8 \mathrm{~nm}$ for the foam obtained from the nitric acid modified pitch. In contrast, the volume of narrow micropores was found to be much lower for sample CFS, indicating that in this case -when sulfuric acid is used to modify the composition of the pitch- the formation of an incipient microporosity is largely reduced.

After steam activation, the opening of the carbon matrix to form a porous structure was evident in both materials, and the activated foams displayed an open structure of interconnected pores with a micro/mesoporous network. The textural characterization showed important differences depending on the type of the acid used to modify the composition of the initial pitch, pointing out the significant influence of the precursor composition on the final structure and properties of the activated carbon foams.

The activation proceeded to a much larger extent when nitric acid was employed to modify the pitch (porosity parameters are twice higher). The effect was also evident in the narrow microporosity (Figures 1 and 2); the $\mathrm{CO}_{2}$ adsorption isotherm of sample $\mathrm{CFN}$-A shows a well defined concavity from low relative pressures, characteristic of a highly microporous material and confirmed that the activation of foam CFN proceeds through the formation of new porosity. The $\mathrm{CO}_{2}$ adsorbed volume in CFN-A was much larger than that of CFS-A in the whole range of relative pressures. The micropore size distribution obtained by the DS method (Figure 3) 
confirmed these observations. The activation of CFS brought about a small opening of the existing pores - the average size of the pristine foam (CFS) remained almost unchanged despite the increase in the pore volume (CFS-A)-, whereas in the case of CFN-A, the increase in the micropore volume upon activation is accompanied by the widening of the microporosity.

It should also be highlighted the short time applied during the steam activation (ca. 60 minutes), compared to the much longer times usually employed in the manufacturing of activated carbons [28]. Despite of this, the resulting activated carbon foam exhibited a relatively large surface area of $930 \mathrm{~m}^{2} / \mathrm{g}$ and a porous volume of $0.40 \mathrm{~cm}^{3} / \mathrm{g}$. Such high surface areas in carbon foams have been reported only after chemical activation of carbon foams using high activating agent ratio $[29,30]$.

These structural differences between both activated carbon foams must be related to the differences in the chemical composition and macromolecular structure of the precursors. First of all, the morphology of the carbon foams was preserved during activation, as inferred from the images shown in Figure 1. On the other hand, the elemental analysis of the carbon foams showed a considerable reduction in the hydrogen and oxygen content in the carbon foam produced from the pitch modified in sulfuric acid, compared to the one treated in nitric acid. Thus CFS has a more dense structure (higher $\mathrm{C} / \mathrm{H}$ ratio) and thus is a more thermostable material than $\mathrm{CFN}$; as a result of these features, CFS shows a higher chemical resistance to oxidation. This is consistent with the easier steam activation observed for CFN.

The investigation of the thermal behavior of the carbon foams (Figure 4) provided additional experimental results which support the higher reactivity of sample CFN. The mass loss corresponding to the thermal degradation (under inert atmosphere) of CFS is almost negligible, thereby confirming the thermal stability of this material. In contrast, the corresponding mass loss for CFN accounted for ca. 7 wt. $\%$, with a wide peak above $600{ }^{\circ} \mathrm{C}$ (the temperature of the 
foaming process). The thermal analysis of the treated pitches (PS and PN samples) before foaming showed that most of the volatiles decomposed at temperatures below $600{ }^{\circ} \mathrm{C}$. Thus the peak observed in the case of the CFN foam could be attributed to the internal structural reorganization of the modified pitch (PN) during the foaming process.

According to the results displayed in Table 1, the polymeration and condensation processes that take place during the foaming process strongly modify the chemical composition of the "green" foams. Thus, the lower $\mathrm{C} / \mathrm{H}$ ratio obtained for sample $\mathrm{CFN}$, along with the degradation peak above $600^{\circ} \mathrm{C}$ suggests that the nitric acid modification changes the polymerization pathway of the pitch during the foaming process. Sulfuric acid seems to catalyze condensation reactions through the formation of large condensed polyaromatic molecules rendering a denser carbon structure characterized by a weak reactivity towards steam activation. At converse, nitric acid modification of the pitch leads to the insertion of heteroatoms in the carbon skeleton (Table 1) that decompose easily with temperature and thus render the material more prone to react with steam during the activation.

XRD analysis was used for determination of the structural transformations of the green and activated carbon foams (Figure 5). The XRD patterns of the prepared carbon foams corroborated the strong dependence of the carbon foam structure on the chemical composition of the modified pitches used as precursors. The more intense narrow (002) peak (characteristic of interlayer spacing) in CFS clearly indicates a considerably higher degree of graphitization and more ordered structure for this material, compared to the sample prepared using the nitric acid modified pitch. The treatment in sulfuric acid provokes polycondensation reactions during the foaming process, that would promote the reorganization of the carbon skeleton in an ordered array (through transformation of the aromatic molecular compounds), reducing the steam 
reactivity and thus the porosity development. After activation, both materials present a more disorganized structure, with a widening of the reflections at $24^{\circ}$ and $44^{\circ}$.

\section{Conclusions}

Carbon foams with tailored textural properties were successfully synthesized from pitches modified with mineral acids by a low pressure foaming process. The choice of the chemical modification of the pitch precursor must be done carefully as it strongly modifies the chemical composition, morphology, structure and reactivity of the resulting carbon foam. Our results showed that while sulfuric acid favours the formation of carbon foams with a dense and ordered structure, nitric acid favours the insertion of heteroatoms in the carbon skeleton. These differences play an important role on the development of the porosity when these foams are activated under steam.

While the modification of the pitch with nitric acid favours the reactivity of the carbon foam towards steam activation, treatment with sulfuric acid renders a denser carbon structure characterized by a weaker reactivity towards physical activation. As result, textural parameters obtained for the activated carbon foam from nitric thermo-oxidized pitch are twice larger than those obtained for sulfuric acid.

These porous features along with the high mechanical and chemical resistance of the carbon foams open up new perspectives in the performance of carbon foams, such as their application as catalyst supports in advanced processes for wastewater remediation.

\section{Acknowledgments}

Authors greatly appreciated the funding from project CC02-221/17.12.2008 with Bulgarian National Science Fund. COA thanks the Spanish MICINN for financial support (grant 
CTM2008-01956 and CTM2011-23378). LFV thanks CSIC for her JAE-predoc contract.

\section{References}

[1] M. Inagaki, New Carbons: Control of Structure and Functions, Elsevier Sci. Ltd., Oxford, 2000, pp. 1-13.

[2] D. Rogers, J. Plucinski, P. Stansberry, A. Stiller, J. Zondlo, In: Proceedings of the International SAMPE Symposium Exhibition, 45, New York, 2000, pp. 293-305.

[3] M. Inagaki, T. Morishita, A. Kuno, T. Kito, M. Hirano, T. Suwa, Carbon 42 (2004) 497-502.

[4] G. Harikrishnan, T.U. Patro, D.V. Khakhar, Carbon 45 (2005) 531-535.

[5] Y. Chen, B. Chen, X. Shi, H. Xu, Y. Hu, Y. Yuan, Carbon 45 (2007) 2132-2134.

[6] M. Liu, L. Gan, F. Zhao, X. Fan, H. Xu, F. Wu, Carbon 45 (2007) 3055-3057.

[7] C. Chen, E. Kennel, A. Stiller, P. Stansberry, J. Zondlo, Carbon 44 (2006) 1535-1543.

[8] Z. Min, M. Cao, S. Zhang, X. Wang, Y. Wang, New Carbon Mat. 22 (2007) 75-79.

[9] M. Wang, C. Wang, T. Li, Z. Hu, Carbon 46 (2008) 84-91.

[10] R.D. Klett, High Temperature Insulating Carbonaceous Material, US Patent 3914392, 1975.

[11] R.V.R.A. Rios, M. Martinez-Escandell, M. Molina-Sabio, F. Rodriguez-Reinoso, Carbon 44 (2006) 1448-1454.

[12] M. Kodama, J. Yamashita, Y. Soneda, H. Hatori, K. Kamegawa, Carbon 45 (2007) 1105-1107.

[13] J. Klett, R. Hardy, E. Romine, C. Walls, T. Burchell, Carbon 38 (2000) 953-973.

[14] J.W. Klett, A.D. McMillan, N.C. Gallego, T.D. Burchell, C.A. Walls, Carbon 42 (2004) 1849-1852.

[15] A. Eksilioglu, N. Gencay, M.F. Yardim, E. Ekinci, J. Mater. Sci. 41 (2006) 2743-2748.

[16] R. Mehta, D.P. Anderson, J.W. Hager, Carbon 41 (2003) 2174-2176. 
[17] M. Calvo, R. Garcia R, A. Arenillas, I. Suarez, S.R. Moinelo, Fuel 84 (2005) 2184-2189.

[18] P.Y. Duk, Y. Korai, I. Mochida, J. Mat. Sci. 21 (1986) 424-428.

[19] B. Petrova, T. Budinova, N. Petrov, M.F. Yardim, E. Ekinci, M. Razvigorova, Carbon 43 (2005) 261-267.

[20] B. Tsyntsarski, B. Petrova, T. Budinova, N. Petrov, M. Krzesinska, S. Pusz, J. Majewska, P. Tzvetkov, Carbon 48 (2010) 3523-3530.

[21] L.F. Velasco, B. Tsyntsarski, B. Petrova, T. Budinova, N. Petrov, J.B. Parra B, C.O. Ania, J. Hazard. Mater. 184 (2010) 843-848.

[22] N. Ohta, Y. Nishi, T. Morishita, Y. Ieko, A. Ito, M. Inagaki, New Carbon Mat. 23 (2008) 216-220.

[23] F. Glenk, T. Knorr, M. Schirmer, S. Gütlein, B.J.M. Etzold, Chem. Eng. Tech. 33 (2010) 698-703.

[24] P.J.M. Carrott, R.A. Roberts, K.S.W. Sing, Carbon 25 (1987) 769-770.

[25] M.M. Dubinin, H.F. Stoeckli. J. Colloid Interf. Sci. 75 (1980) 34-42.

[26] G. Tondi, A. Pizzi, L. Delmotte, J. Parmentier, R. Gadiou, Ind. Crop. Prod. 31 (2010) 327-334.

[27] J.M. Juárez-Galán, A. Silvestre-Albero, J. Silvestre-Albero, F. Rodríguez-Reinoso, Microp. Mesop. Mater. 120 (2009) 62-68.

[28] H. Fujita, M. Hijiriyama, S. Nishida, Fuel 62 (1983) 875-879.

[29] B.S. Girgis, L.B. Khalil., T.A.M. Tawfik, J. Porous Mat. 9 (2002) 105-113.

[30] C. Bouchelta, M.S. Medjram, O. Bertrand, J.P. Bellat, J. Anal. Appl. Pyrol. 82 (2008) 70-77. 


\section{Figures Captions}

Figure 1. Figure 1. Top: SEM micrographs of the carbon foam derived from pitch modified with $\mathrm{HNO}_{3}$ (left) and $\mathrm{H}_{2} \mathrm{SO}_{4}$ (right). Down: images of the carbon foams before (left) and after (right) activation.

Figure 2. $\mathrm{N}_{2}$ and $\mathrm{CO}_{2}$ adsorption isotherms at 77 and $273 \mathrm{~K}$, respectively.

Figure 3. Micropore size distribution obtained by the DS method applied to the $\mathrm{CO}_{2}$ adsorption isotherms at $273 \mathrm{~K}$.

Figure 4. XRD of the carbon foams before and after activation.

Figure 5. DTG profiles of the modified pitches and the synthesized carbon foams before and after steam activation.

\section{Tables Captions}

Table 1. Elemental analysis of the modified pitches, and the obtained carbon foams before and after steam activation.

Table 2. Main textural parameters of the obtained carbon foams before and after steam activation. 
Table 1.

\begin{tabular}{llllll}
\hline Sample & $\mathbf{C}$ & $\mathbf{H}$ & $\mathbf{N}$ & $\mathbf{S}$ & $\mathbf{O}$ \\
& $\mathbf{( w t . \% )}$ & $\mathbf{( w t . \% )}$ & $\mathbf{( w t . \% )}$ & $\mathbf{( w t . \% )}$ & $\mathbf{( w t . \% )}$ \\
\hline P & 90.6 & 5.3 & 0.9 & 0.5 & 2.8 \\
PN & 83.9 & 4.2 & 0.8 & 2.6 & 8.4 \\
CFS & 83.7 & 4.4 & 2.1 & 0.4 & 9.5 \\
CFN & 97.6 & 0.6 & 0.6 & 0.8 & 0.4 \\
CFS-A & 90.6 & 1.6 & 2.5 & 0.7 & 4.6 \\
CFN-A & 95.8 & 0.5 & 0.9 & 1.2 & 0.6 \\
\hline
\end{tabular}

Table 2.

\begin{tabular}{|c|c|c|c|c|c|}
\hline Sample & $\begin{array}{l}\mathrm{S}_{\mathrm{BET}} \\
\left(\mathrm{m}^{2} / \mathrm{g}\right)\end{array}$ & $\begin{array}{l}\mathrm{V}_{\text {TOTAL }}{ }^{\mathrm{a}} \\
\left(\mathrm{cm}^{3} / \mathrm{g}\right)\end{array}$ & $\begin{array}{l}V_{\text {micro }}{ }^{b} \\
\left(\mathrm{~cm}^{3} / \mathrm{g}\right)\end{array}$ & $\begin{array}{l}V_{\text {meso }} b \\
\left(\mathrm{~cm}^{3} / \mathrm{g}\right)\end{array}$ & $\begin{array}{l}\mathrm{Wo}^{\mathrm{c}} \\
\left(\mathrm{cm}^{3} / \mathrm{g}\right)\end{array}$ \\
\hline CFN & 22 & 0.020 & 0.011 & 0.010 & 0.100 \\
\hline CFS & 12 & 0.014 & 0.012 & 0.003 & 0.030 \\
\hline CFN-A & 933 & 0.398 & 0.389 & 0.008 & 0.282 \\
\hline CFS-A & 375 & 0.192 & 0.167 & 0.028 & 0.097 \\
\hline \multicolumn{6}{|c|}{ a evaluated at $p / p_{0} \sim 0.99$} \\
\hline \multicolumn{6}{|c|}{$b$ evaluated by the t-plot method applied to $N_{2}$ adsorption isotherms } \\
\hline \multicolumn{6}{|c|}{ c evaluated from the DRS method applied to $\mathrm{CO}_{2}$ adsorption isotherms } \\
\hline
\end{tabular}


Figure 1.
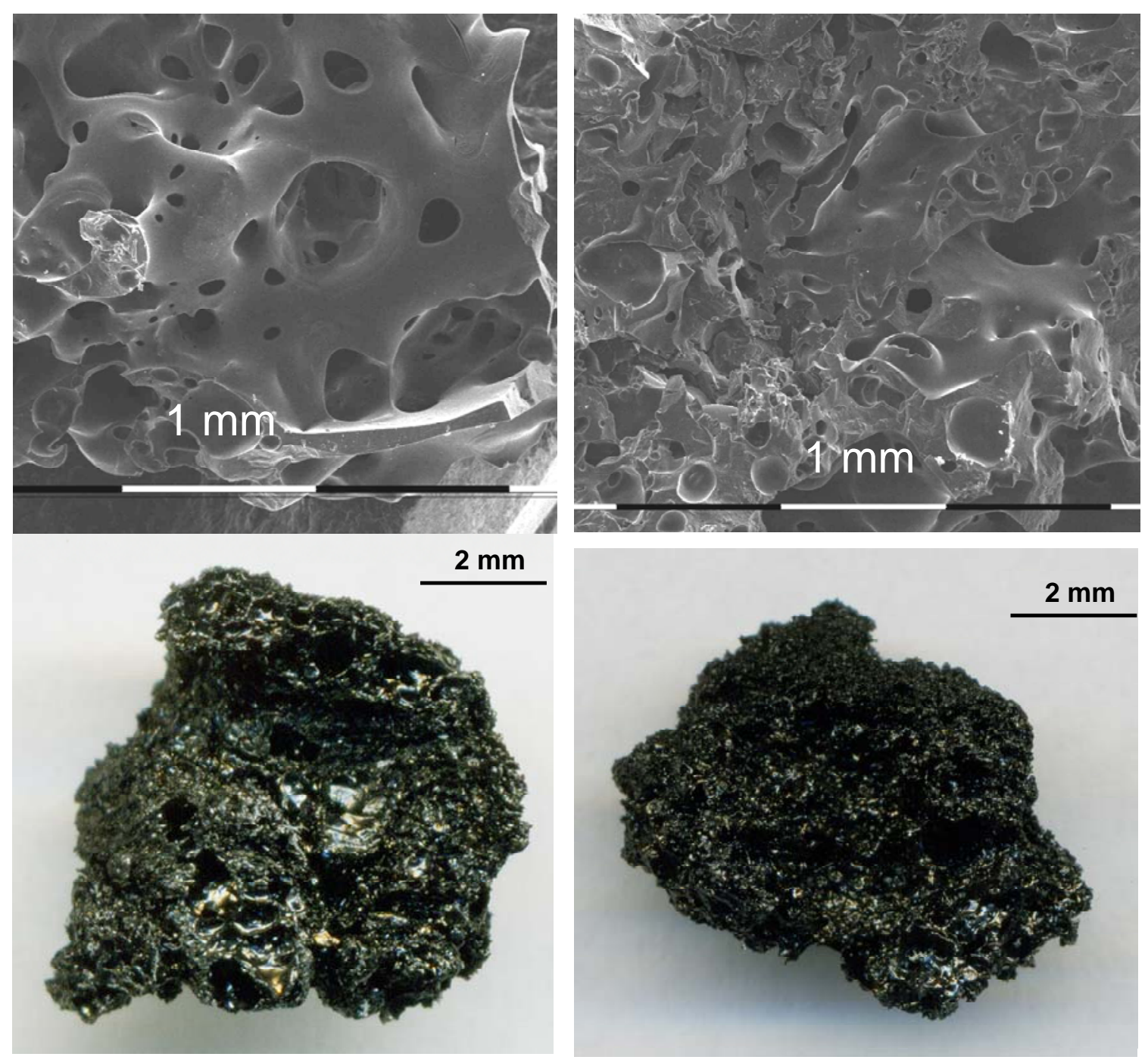
Figure 2.
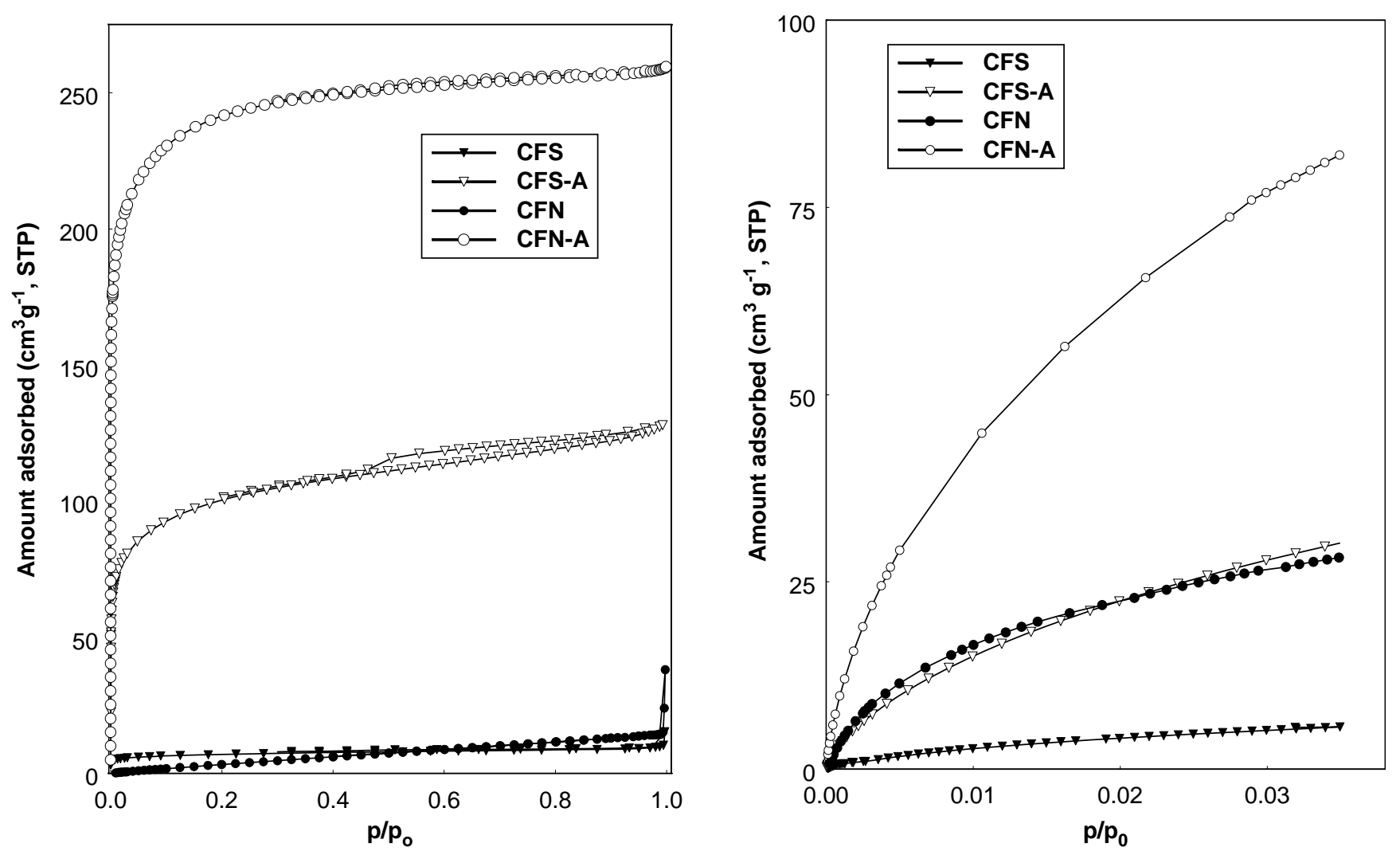
Figure 3.

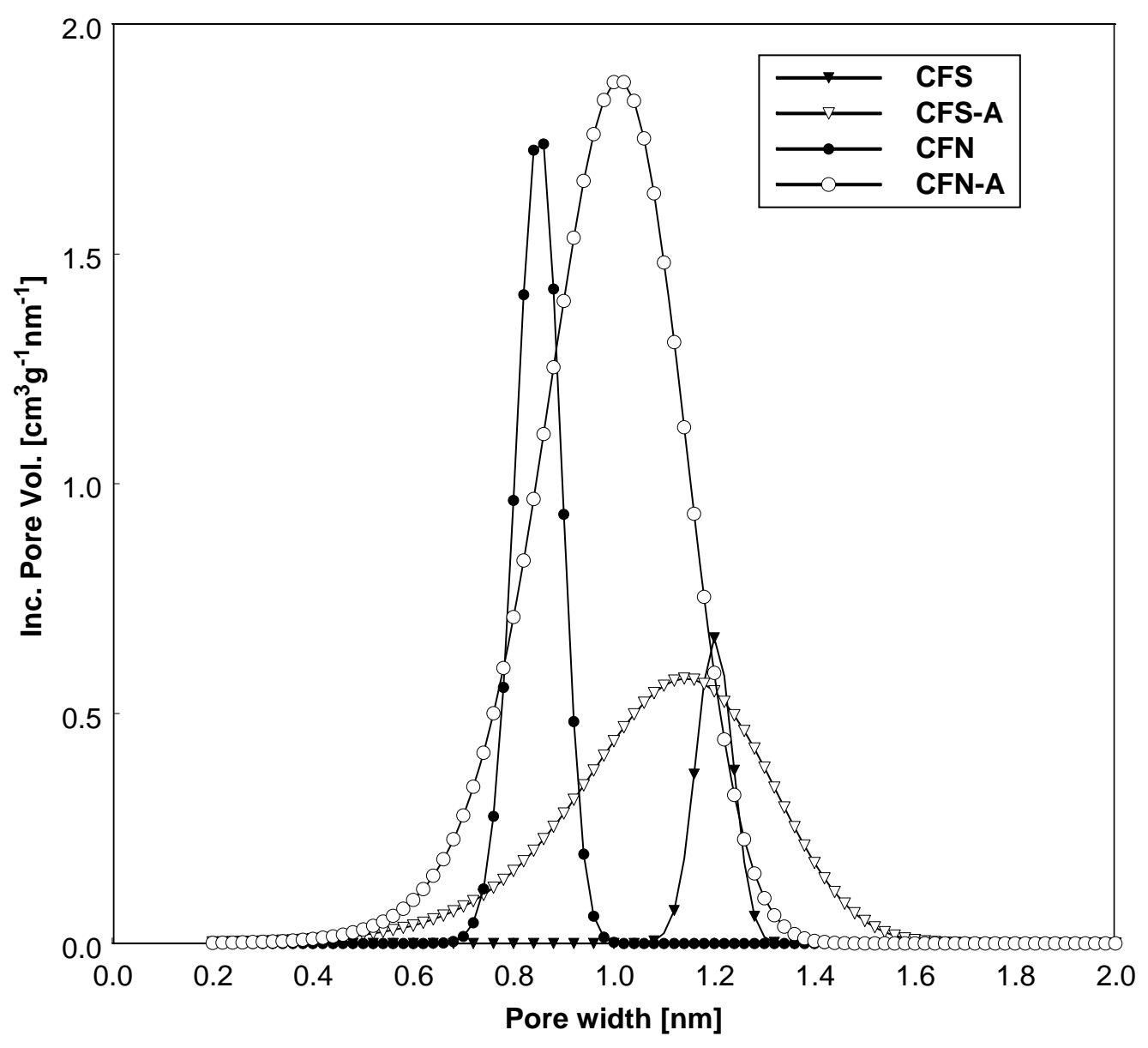


Figure 4.
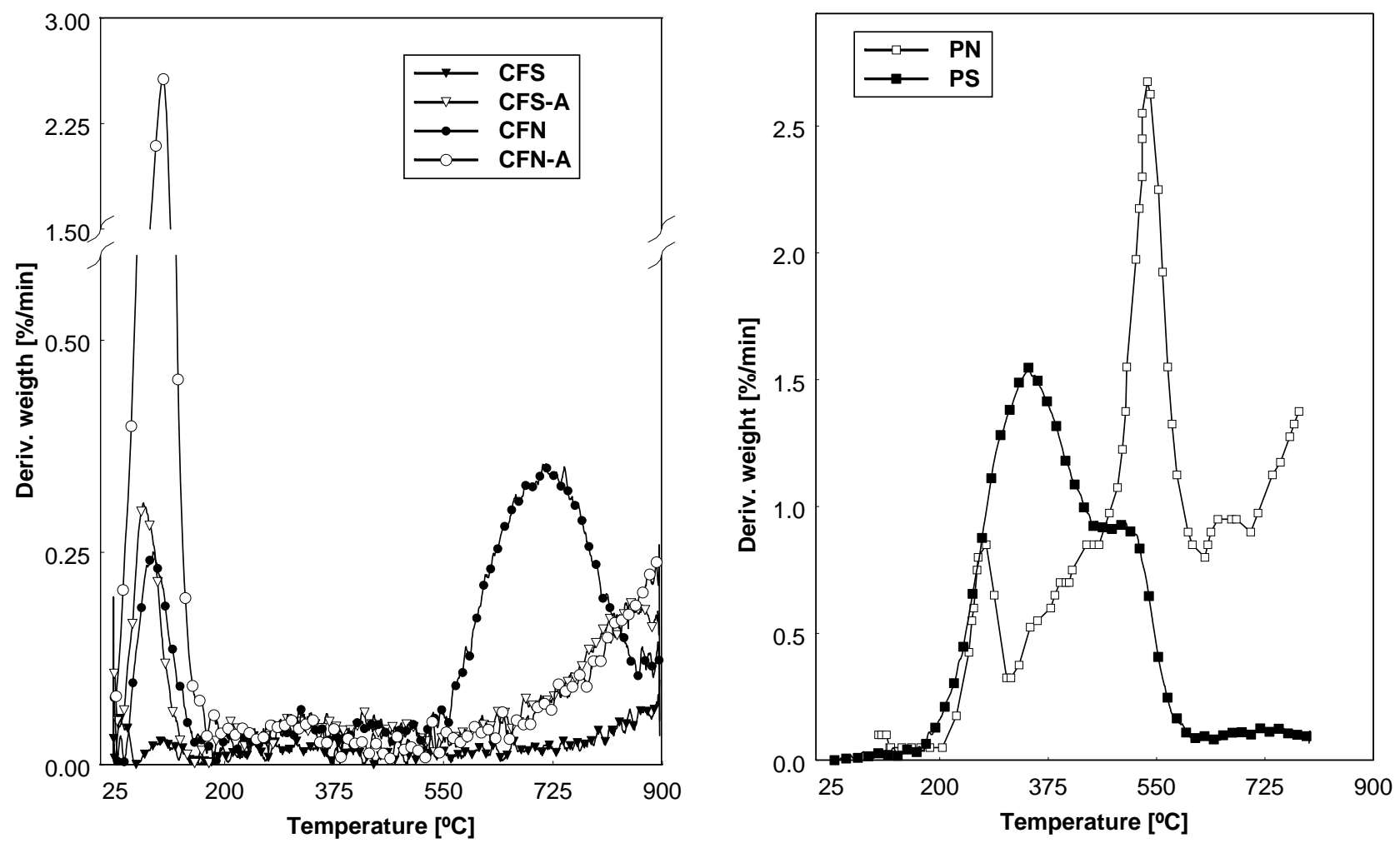
Figure 5.

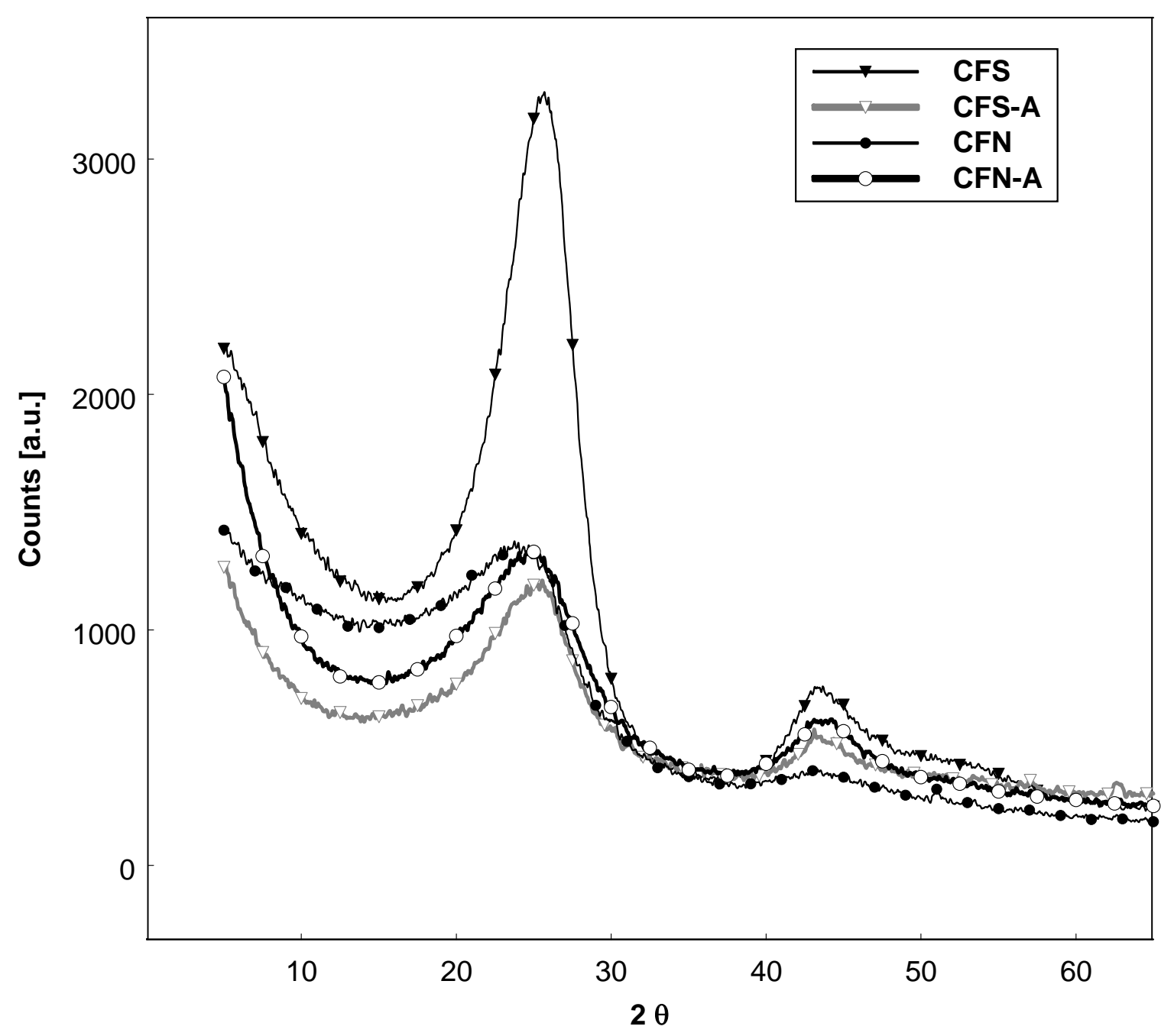

